\title{
"Le Compagnon du tour de France" de George Sand, études réunies par Martine Watrelot et Michèle Hecquet
}

\section{Sonia Gerolimich}

\section{(2) OpenEdition \\ Journals}

\section{Édition électronique}

URL : http://journals.openedition.org/studifrancesi/5679

DOI : 10.4000/studifrancesi. 5679

ISSN : 2421-5856

\section{Éditeur}

Rosenberg \& Sellier

\section{Édition imprimée}

Date de publication : 1 septembre 2011

Pagination : 434-435

ISSN : 0039-2944

\section{Référence électronique}

Sonia Gerolimich, "Le Compagnon du tour de France" de George Sand, études réunies par Martine Watrelot et Michèle Hecquet », Studi Francesi [En ligne], 164 (LV | II) | 2011, mis en ligne le 30 novembre 2015, consulté le 11 janvier 2021. URL : http://journals.openedition.org/studifrancesi/5679; DOI : https://doi.org/10.4000/studifrancesi.5679

Ce document a été généré automatiquement le 11 janvier 2021.

\section{cc) (†) $\odot$}

Studi Francesi è distribuita con Licenza Creative Commons Attribuzione - Non commerciale - Non opere derivate 4.0 Internazionale. 


\title{
"Le Compagnon du tour de France" de George Sand, études réunies par Martine Watrelot et Michèle Hecquet
}

\author{
Sonia Gerolimich
}

\section{RÉFÉRENCE}

AA. VV., "Le Compagnon du tour de France" de George Sand, études réunies par Martine WATRELOT et Michèle HECQUET, Université Charles-de-Gaulle-Lille 3, 2009, 99 pp.

Cet ouvrage rassemble les actes des journées des 8 et 9 décembre 2005 commémorant le bicentenaire des naissances de George Sand (1804) et du compagnon menuisier Agricol Perdiguier (1805). Les quatorze articles portent pour la plupart sur le roman Le Compagnon du tour de France (1840) par lequel Sand a fait connaître au public l'existence du monde ouvrier. Sand, qui s'est surtout inspirée du livre de Perdiguier, Livre du compagnonnage (1839), a pu aussi bénéficier de ses conseils lors des relectures.

Les deux premiers articles se distinguent des autres, dans la mesure où il s'agit de la contribution de membres du monde compagnonnique qui se sont consacrés à la Mémoire ouvrière. Tous deux présentent à leur manière le monde du compagnonnage, qui a pu devenir source d'études grâce à Perdiguier et Sand et dont on peut mesurer l'intérêt actuel. Jean-Paul CHAPELLE (pp. 15-21) fait le bilan des diverses manifestations et collaborations qui ont participé à cette commémoration dans toute la France. Thierry COURTIN (pp. 23-27) nous informe des difficultés rencontrées pour l'archivage des documents. Il fait l'inventaire des musées et archives existants à ce jour, souhaitant que les chercheurs approfondissent davantage la connaissance du monde ouvrier. Il souligne l'importance de la transmission pour les générations futures de cette histoire des Compagnons, qui ont eu un important rôle d'éducateurs dans tous les domaines et 
ont servi de modèle aux diverses associations ouvrières, tels que les syndicats ou les mutuelles.

3 Les contributions qui suivent sont essentiellement consacrées à l'analyse du roman de Sand. Elles ont été regroupées suivant quatre thématiques: «la politique», «la poétique», «le peuple et l'art» et «l'accueil de l'œuvre». Toutefois, c'est surtout l'engagement de Sand en faveur des idées républicaines et du développement social du peuple, qui est chaque fois mis en évidence, en particulier dans les $1^{\text {re }}$ et $2^{\mathrm{e}}$ parties.

4 Jean-Louis CABANÈs (pp.31-40) examine la façon dont Sand dénonce les attitudes manipulatrices et faussement progressistes du comte de Villepreux, capable de leurrer les porte-parole du peuple, comme Achille Lefort. Deux études évoquent les influences qui ont marqué Sand et qu'elle a transposées dans son roman. Olivier BARA (pp. 41-52) souligne le rapprochement, tout à fait légitime, entre Pierre Huguenin, le héros du Compagnon, et Rousseau, en tant que représentant de «l'artisan éclairé». La mise en scène de ce personnage permet de mettre en évidence certaines tensions, comme l'opposition entre «arts utiles» et «Beaux-arts» ou entre l'idéal d'autonomie de l'artisan et les modèles de solidarité des sociétés ouvrières. Pierre Huguenin correspond bien à la description que Sand fait de Rousseau dans un article de 1841: un «homme pensif», transporté par des idéaux et par l'espoir dans le progrès humain, mais incapable de toute action concrète. Bruno VIARD (pp. 53-60), de son côté, retrace la figure de Pierre Leroux, référence capitale pour Sand. Il rappelle la vision "anti-manichéenne» de Leroux, condamnant toute prise de position absolutiste, que ce soit dans l'individualisme ou le socialisme. Il met en évidence le choix de Sand de se limiter à mettre en scène, à travers le personnage d'Huguenin, uniquement les débuts initiatiques du jeune Leroux, tiraillé entre ses «aspirations généreuses» et «son angoisse devant le problème social», ce qui conduit l'auteur à considérer Le Compagnon avant tout comme un «roman de formation».

5 L'engagement de Sand au niveau politique et social est relevé aussi par Michèle HECQUET (pp.61-69) qui, en se référant à l'Avant-propos du roman et à ses premières pages, retrace la rencontre de Sand et de Perdiguier et leur influence réciproque. En outre M. Hecquet, comme O. Bara d'ailleurs, se penche sur les sociétés secrètes, telles que les carbonari. Marie-Claude SCHAPIRA (pp. 73-85) et Claire BAREL-MOISAN (pp. 87-100) s'accordent pour considérer le roman de Sand comme une tentative d'éveiller la conscience politique du lecteur. Elles soulignent le poids que peut avoir la «science des livres» auprès de la classe ouvrière, en particulier à travers Pierre et Amaury le Corinthien. Claire Barel-Moisan montre que ce roman n'aboutit à aucune solution, ce qui empêche de le considérer comme un roman à thèse. M.-C. Schapira réussit à expliquer comment cette œuvre avant tout axée sur la «question sociale» reste malgré tout un vrai roman qui met en scène deux histoires parallèles d'amour, marquées cependant par la «désolation» et la souffrance. Ces sentiments négatifs sont surtout le fait de l'acculturation, de la difficulté à rapprocher le monde aristocratique du prolétariat mais aussi de la perte de l'innocence, dévoyée par l'accès à la culture. Catherine MARIETTE-CLOT (pp.101-111) souligne le refus de Sand des modèles romanesques en vogue tels que le roman historique ou le roman sentimental; Sand préfère placer son roman dans une histoire en marche, n'appartenant pas au passé.

6 Les articles de la $3^{\mathrm{e}}$ partie illustrent «le rapport du peuple et de l'art». Nathalie VINCENTMUNNIA (pp. 115-128) montre que la poésie populaire constitue un «bouleversement socio-historique» puisqu'elle supprime les frontières entre les domaines manuel et 
intellectuel. Elle décrit la façon dont Sand fait la célébration de cette culture populaire, qui tente de concilier réalisme et idéalisation, dans une perspective prophétique, appelée à transformer les idéaux en réalité. Sophie Anne LETERRIER (pp.129-141), retrace la nouvelle conception de l'art qui se fait jour au xix ${ }^{e}$ siècle, en montrant les nombreuses hiérarchies existantes. Elle s'applique également à montrer l'opposition entre Amaury, l'artiste qui échoue, dont le but principal est celui de sortir de sa classe sociale, et Pierre, qui arrive à atteindre «l'art du trait», grâce à la culture et au travail qu'il fait sur lui-même. Claudine GRossiR (pp.143-152) axe sa réflexion sur le rôle central de la restauration de la chapelle de Villepreux dans le roman. En effet, ce sujet permet à la romancière d'inscrire son roman dans la continuité historique, surtout dans la "persistance révolutionnaire», et d'exposer sa conception concernant les figures de l'artisan et de l'artiste.

7 Les deux contributions qui clôturent cet ouvrage se sont penchées sur «l'accueil de l'œuvre». Quoiqu'il soit difficile de mesurer l'impact qu'a pu avoir le roman sur le public de l'époque, Martine WAtrelot (pp.155-167) explique qu'il est plutôt considéré comme une lecture utile, comme une «archive de l'histoire du réveil intellectuel du monde ouvrier». Jean-François CHANET (pp. 169-181) décrit la distance entre la vision du peuple que Jean Jaurès s'est faite à partir du Compagnon et celle qu'en donne Sand. En effet, selon lui, les travailleurs seraient «sortis du chaos intellectuel» à cette époque-là, alors qu'il s'agit encore pour le peuple d'accéder à une prise de conscience, qui n'est accessible qu'au prix du travail, de l'étude, en peu de mots qu'au moyen de la «foi rédemptrice».

Dans l'ensemble les différentes contributions tendent à se recouper; cela confirme néanmoins la justesse de leurs analyses, abordées sous une perspective à chaque fois différente. 